\title{
The Effect of Otago Exercise Program on TNF-a Serum Levels in Elderly Women at Nursing Homes in Surabaya
}

\author{
Lady Saeranga, Sri Mardjiati Mei Wulan a,a, Subagyo, \\ Soenarnatalina Melaniani ${ }^{\mathrm{b}}$, Rwahita Satyawati ${ }^{\mathrm{a}}$, Nuniek Nugraheni ${ }^{\mathrm{a}}$ \\ ${ }^{a}$ Corresponding author: meiwulan21@gmail.com
}

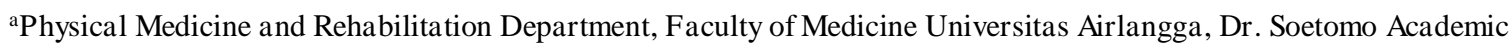
General Hospital, Surabaya, Indonesia

${ }^{b}$ Department of Epidemiology, Demography Biostatistics and Health Promotion and Behaviour, Faculty of Public Health, Universitas Airlangga, Surabaya, Indonesia

\begin{abstract}
Background: Increasing age is a contributing factor for increasing inflammatory status. Increased levels of proinflammatory cytokines are associated with decreased physical function and increased risk of various diseases. Tumor necrosis factor-alpha (TNF- $\alpha$ ) is a pro-inflammatory cytokine that plays a role in the aging process and age-related diseases. The Otago exercise program is a fall prevention program for the elderly, effectively increasing muscle strength, balance, and physical performance in the elderly.

Objective: To evaluate the effect of the Otago exercise program for 8 weeks on serum TNF- $\alpha$ levels in elderly women in nursing homes.

Method: This study was conducted from October to December 2020. Twenty-six elderly women living in nursing homes at Surabaya were recruited and randomized into the control and treatment groups. The treatment group performed the Otago exercise program for 8 weeks and the control group received no intervention. Peripheral blood samples for serum TNF- $\alpha$ were collected in two days pre-training and two days post-training.

Result: Within-group comparison in intervention and control group; and between group comparison of serum TNF- $\alpha$ levels, showed no significant difference $(p=0,407, p=0,112$, and $p=0,524$, respectively).

Conclusion: The Otago exercise program for 8 weeks showed no significant effect on serum TNF- $\alpha$ levels in elderly women.
\end{abstract}

Keywords: Otago exercise program; Elderly; Women; serum TNF- $\alpha$ levels; Indonesia

\section{Introduction}

Increasing age is a contributing factor to the increase in inflammatory status in the elderly. There was an increase in the levels of interleukin (IL)-6, IL-18, IL-1 receptor antagonist, C-reactive protein (CRP), and tumor necrosis factor-alpha (TNF- $\alpha$ ) which continued to increase with age. Studies have consistently shown that high levels of inflammatory markers are associated with decreased physical function and increased risk of various diseases, loss of skeletal muscle mass and function, while physical activity is associated with increased levels of systemic inflammation in the elderly. Inflammation is a strong predictor of disability and death in the elderly even in the absence of clinical disease (Nicklas and Brinkley, 2009). 
Tumor necrosis factor-alpha is a biological marker that can be detected in plasma or serum, has an important role in the regulation of inflammation, and played an important role in the aging process and agerelated diseases. TNF- $\alpha$ expression significantly increased in the elderly group compared to the middle age group. High levels of TNF- $\alpha$ is associated with mortality, dementia, Alzheimer's, atherosclerosis, loss of muscle and bone mass to frailty in the elderly that cause functional disability, therefore TNF- $\alpha$ is a good biological marker of aging (Calvo et al., 2010).

The Otago exercise program is a fall prevention program for the elderly. The program consists of 17 exercises, 5 strengthening exercises, and 12 balance exercises with progression in intensity or balance challenge (Campbell and Robertson., 2003; Shubert et al., 2018). Regular physical exercise can improve chronic inflammatory conditions in the elderly. Regular physical exercise with moderate intensity such as walking, cycling, weight training is beneficial in reducing the risk of death, stroke, cardiovascular disease, and type 2 diabetes mellitus, as well as reducing the risk of sarcopenia, dementia, depression, physical dependence, and improved physical function in the elderly, improved chronic inflammation condition and prevent diseases associated with chronic inflammation in the elderly (Petersen et al., 2005; Allen, 2017). Weight or strengthening exercises in the elderly have been shown to significantly reduce serum TNF- $\alpha$ levels (Sabbagh et al., 2015; Santiago et al., 2018).

\section{Material and Method}

This research was conducted at nursing homes in Surabaya, Indonesia in October - December 2020 with a pre and post-test randomized control group design. The study aimed to evaluate the effect of an 8-week Otago exercise program on serum TNF- $\alpha$ levels in elderly women in a nursing home. Research subjects were selected by cluster random sampling method. Twenty-six elderly women subjects who met the inclusion criteria and were not included in the exclusion criteria were divided into the intervention group and the control group, thirteen subjects in each group. The participants inclusion criteria were: (1) an elderly woman, age 60 years old or more; (2) living in nursing home at Surabaya; (3) able to ambulate independently without assistive devices; (4) hemodynamically stable; (5) having sufficient vision and hearing capacity to participate in the exercise (6) signing the consent form to be the subject of the study. Exclusion criteria were: (1) the subject had participated in regular strengthening exercises with weights in 1 month before; (2) fractured lower limbs that interfered with ambulation function; (3) have moderate to severe cognitive disturbance; (4) suffered from vertigo. Parameters assessed were serum levels of TNF- $\alpha$. Blood samples were taken 2 days before and 2 days after treatment. The treatment group performed the Otago exercise program for 8 weeks, consisting of 5 types of strengthening exercises, 12 balance exercises, with a frequency of 3 times per week, with a total training time of \pm 30 minutes. Control group subjects received education about a healthy lifestyle (figure 1).

Statistical test was used SPSS 23.0 with a significance level of $\mathrm{p}<0.05$, parametric statistical test if the data was normally distributed and non-parametric if the data was not normally distributed. Comparing $\mathrm{TNF}-\alpha$ serum levels before and after treatment in each group (control and intervention), paired t-test data was used to identify the variables with normal distribution, or the Wilcoxon Signed-Rank test was used to compare non normally distributed variables. Comparing the difference pre and post serum TNF- $\alpha$ levels between the intervention and control groups, the unpaired t-test was used if the data were normally distributed or the Mann-Whitney test was used if the data were not normally distributed.

Ethical eligibility has been obtained from the Ethics Commission for basic science/clinical research at the Faculty of Medicine, Airlangga University, Surabaya, 241/EC/KEPK/FKUA/2020 dated October 1, 2020 . 


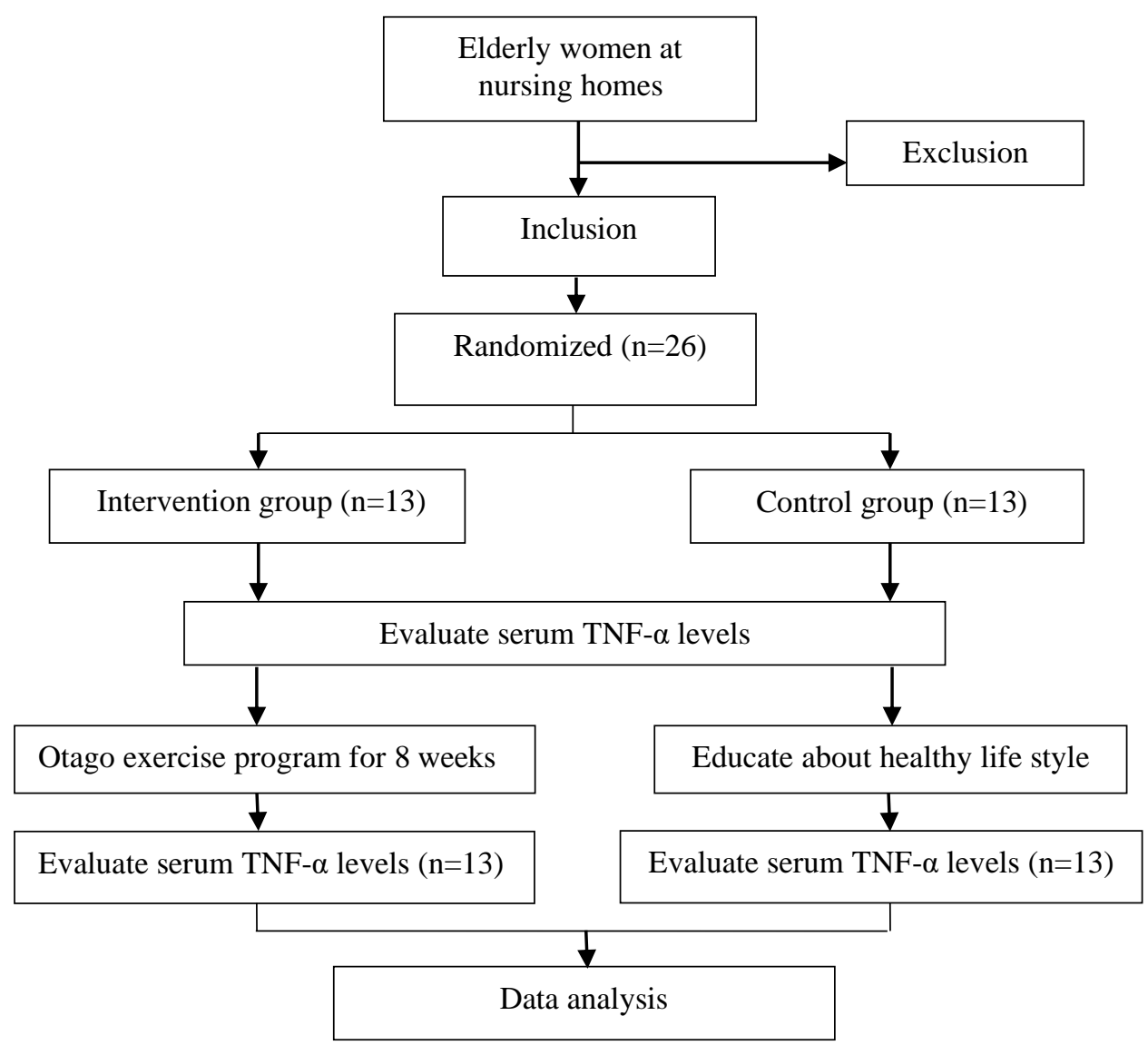

Figure 1. Flow diagram

\section{Result}

Demographic characteristics include age, body weight, body height, body mass index, and TNF- $\alpha$ level. The homogeneity test showed that the demographic characteristics between the two groups were homogeneous ( $\mathrm{p}$-value >0.05) (Table 1). In the intervention group, the mean serum TNF- $\alpha$ level before being given Otago exercise was $2.43 \pm 0.78 \mathrm{pg} / \mathrm{ml}$, and the mean after being given intervention for 8 weeks was $2.58 \pm 0.66 \mathrm{pg} / \mathrm{dl}(\mathrm{p}=0.407)$ and in the group control, the mean initial serum TNF- $\alpha$ level was $2.42 \pm 0.82 \mathrm{pg} / \mathrm{ml}$, and the mean serum TNF- $\alpha$ level at the final evaluation was $2.72 \pm 0.62 \mathrm{pg} / \mathrm{ml} .(\mathrm{p}=0.112)$ Based on the paired $\mathrm{t}$ statistical test, there were no significant differences in serum TNF- $\alpha$ levels before and after the intervention in the treatment group and the control group ( $>0.05$ ) (Table 2). The mean delta of TNF- $\alpha$ serum levels in the treatment group was $0.14 \pm 0.60 \mathrm{pg} / \mathrm{ml}$ and $0.29 \pm 0.62 \mathrm{pg} / \mathrm{ml}$ in the control group. Based on the unpaired t-test, there was no significant difference in the mean delta of serum TNF- $\alpha$ levels between the two groups after 8 weeks of treatment $(\mathrm{p}=0.524)$ (Table 3$)$. 
Table 1 Demographic characteristic of subjects

\begin{tabular}{lccccc}
\hline \multicolumn{1}{c}{ Characteristics } & $\begin{array}{c}\text { Intervention Group } \\
(\mathrm{n}=13)\end{array}$ & $\begin{array}{c}\text { p-value } \\
(\text { normality })\end{array}$ & $\begin{array}{c}\text { Control Group } \\
(\mathrm{n}=13)\end{array}$ & $\begin{array}{c}\mathrm{p} \text {-value } \\
\text { (normality) }\end{array}$ & $\begin{array}{c}\text { p-value } \\
\text { (homogeneity) }\end{array}$ \\
\hline Age (years) & $74,31 \pm 6.21$ & 0,347 & $75,31 \pm 9,01$ & 0,557 & 0.745 \\
\hline Body weight $(\mathrm{kg})$ & $45,72 \pm 9,04$ & 0,538 & $49,33 \pm 9,04$ & 0,598 & 0.365 \\
\hline Body height $(\mathrm{cm})$ & $148,85 \pm 5,91$ & 0,219 & $146,92 \pm 7,78$ & 0,417 & 0.485 \\
\hline $\begin{array}{l}\text { Body Mass Index } \\
\left(\mathrm{kg} / \mathrm{m}^{2}\right)\end{array}$ & $20,56 \pm 3,33$ & 0,628 & $22,62 \pm 3,35$ & 0,802 & 0.130 \\
\hline TNF- $\alpha$ serum (pg/ml) & $2,43 \pm 0,78$ & 0,269 & $2,42 \pm 0,82$ & 0,169 & 0,968 \\
\hline
\end{tabular}

Table 2. TNF- $\alpha$ serum levels change in intervention and control group

\begin{tabular}{ccccccc}
\hline & \multicolumn{2}{c}{ Intervention Group $(\mathrm{n}=13)$} & \multicolumn{3}{c}{ Control group $(\mathrm{n}=13)$} \\
\hline & Before & After & p-value & Before & After & p-value \\
\hline $\mathrm{TNF}-\alpha(\mathrm{pg} / \mathrm{ml})$ & $2,43 \pm 0,78$ & $2,58 \pm 0,66$ & 0,407 & $2,42 \pm 0,82$ & $2,72 \pm 0,62$ & 0,112 \\
\hline
\end{tabular}

Table 3. Comparison of TNF- $\alpha$ serum levels change after 8 weeks

\begin{tabular}{lccc}
\hline & Intervention Group $(\mathrm{n}=13)$ & Control group $(\mathrm{n}=13)$ & $\mathrm{p}$-value \\
\hline$\Delta \mathrm{TNF}-\alpha(\mathrm{pg} / \mathrm{ml})$ & $0,14 \pm 0,60$ & $0,29 \pm 0,62$ & 0,524 \\
\hline
\end{tabular}

\section{Discussion}

The results of this study showed that there was no difference in serum TNF- $\alpha$ levels in the treatment group after giving the Otago exercise program for 8 weeks or in the control group after 8 weeks of observation. In line with this study, Salamat, et al (2016) reported that there was no significant difference in TNF- $\alpha$ levels between the group given endurance, strengthening, combined strengthening with endurance training and the control group after 8 weeks of exercise in overweight male subjects, and there was a tendency to increased TNF- $\alpha$ levels. In contrast to the results of this study, Tomeleri, et al (2016) reported that 8 weeks of upper and lower extremity strengthening exercises in elderly women caused a significant decrease in IL-6, TNF- $\alpha$, and CRP levels. Strengthening exercise causes a decrease in cytokine levels by initiating skeletal muscle to produce anti-inflammatory myokines which are antagonists of pro-inflammatory cytokines, thereby causing an improvement in anti-inflammatory conditions. Santiago et al (2018), reported the effect of upper and lower extremity strengthening exercises for 8 weeks in elderly women significantly reduced levels of IL6 , TNF- $\alpha$, TNF- $\alpha$ gene expression, and CRP. This condition is caused by modulation of the immune system and anti-inflammatory effects, where strengthening exercises caused the release of cytokines, especially IL-6 which acted as a TNF- $\alpha$ antagonist during exercise.

The possibility that there is no decrease in serum TNF- $\alpha$ levels after giving the Otago exercise program for 8 weeks due to the exercise that only involved the lower limb muscles with an exercise duration of only about 30-45 minutes per session including strengthening and balance exercises. Research by Tomeleri 
et al (2016) and Santiago et al (2018), resulted in improvements in TNF- $\alpha$ levels doing upper and lower extremity strengthening exercises with a strengthening exercise time of 45-50 minutes per session. Skeletal muscle contraction produced and released several cytokines (myokine), especially IL-6, increasing antiinflammatory cytokines, cause a decrease in TNF- $\alpha$ production (Petersen, 2005; Nicklas and Brinkley, 2009). Strengthening exercises that involved the muscles of the upper and lower limbs involved more muscle contraction, resulting in a better inflammatory repair response. The difference in the type and duration of the exercise given can be a factor that does not get changes in TNF- $\alpha$ levels in this study.

Miguelez et al (2015) conducted a study on the effect of 8 weeks of exercise with whole-body vibration on TNF- $\alpha$ levels, which resulted in a significant decrease in TNF- $\alpha$ levels in the intervention group but not in the control group. The evaluation of TNF- $\alpha$ levels was carried out 5 days after the intervention, in contrast to this study the evaluation of TNF- $\alpha$ levels was carried out 2 days after the intervention. The different timing of the TNF- $\alpha$ examination after the intervention may be a factor that influenced the differences in the findings of this study. Allen et al (2015) stated that a time of 1.5 to 24 hours after exercise caused an initial pro-inflammatory response which was then followed by an anti-inflammatory response to muscle regeneration at 24 to 72 hours after exercise. The interval of 2 days after exercise may not be enough time able to see a decrease in TNF- $\alpha$ levels in elderly subjects due to a decrease in the immune system response in the elderly.

A systematic review by Monteiro et al (2018) regarding the effect of exercise on the inflammatory profile in the elderly suggested that various processes affect the production of TNF- $\alpha$ (exercise, diet, smoking, aging). A short intervention period may not be sufficient to detect changes in biological markers in the elderly, and a longer intervention period may not show changes in inflammatory marker levels due to the susceptibility of the elderly to uncontrollable environmental factors (acute infections and rheumatic diseases) that can affect cytokine levels, then the different types of exercise given had different effects on the levels of inflammatory markers. High TNF- $\alpha$ levels at baseline showed a decrease after exercise but low TNF- $\alpha$ levels at baseline did not show significant changes (Monteiro et al, 2018). High concentration when TNF- levels> $3.20 \mathrm{pg} / \mathrm{ml}$ (Visser et al, 2002). The concentration of TNF- $\alpha$ in this study which was still in the normal range could be another factor that caused no decrease in TNF- $\alpha$ levels after the intervention.

\section{Conclusion}

There was no decrease in TNF- $\alpha$ levels in elderly women subject after performed eight weeks Otago exercise program neither in the control group. There was a tendency to increased TNF- $\alpha$ serum levels in both groups, but the increase in TNF- $\alpha$ serum levels in the group that perform the Otago exercise program was lower than the control group.

\section{References}

Allen, J., Sun, Y., \& Woods, J. A. 2015. Exercise and the regulation of inflammatory responses. Progress in molecular biology and translational science, $135,337-354$.

Allen, S. C. 2017. Systemic inflammation in the genesis of frailty and sarcopenia: an overview of the preventative and therapeutic role of exercise and the potential for drug treatments. Geriatrics, 2(1), 6.

Calvo, D., Neitzert, K., Fernández, M., Vega-Naredo, I., Caballero, B., García-Macía, M., Coto-Montes, A. 2010. Differential inflammatory responses in aging and disease: TNF- $\alpha$ and IL-6 as possible biomarkers. Free Radical Biology and Medicine, 49(5), 733-737.

Campbell, A. J., \& Robertson, M. C. 2003. Otago exercise programme to prevent falls in older adults. Wellington: ACC Thinksafe, 3.

Miguelez, R. P., Fernandez-Gonzalo, R., Collado, P. S., Almar, M., Martinez-Florez, S., de Paz, J. A., Gallego, J. G. and Cuevas, M. J. 2015. Whole-body vibration improves the anti-inflammatory status in elderly subjects through toll-like receptor 2 and 4 signaling pathways. Mechanisms of ageing and development, 150, 12-19.

Monteiro-Junior, R. S., de Tarso Maciel-Pinheiro, P., Portugal, E. D. M. M., da Silva Figueiredo, L. F., Terra, R., Carneiro, L. S., 
Rodrigues, V.D., Nascimento, O. J., Deslandes, A. C., Laks, J. 2018. Effect of exercise on inflammatory profile of older persons: systematic review and meta-analyses. Journal of Physical Activity and Health, 15(1), 64-71.

Nicklas, B.J. and Brinkley, T.E. 2009. Exercise training as a treatment for chronic inflammation in the elderly. Exercise and sport sciences reviews, 37(4), p.165.

Petersen, A.M.W. and Pedersen, B.K. 2005. The anti-inflammatory effect of exercise. Journal of applied physiology, 98(4), pp.11541162. Philadelphia.

Sabbagh, El. N. M., Shahin, E. M., El Makarem, N. H. A., Swelem, R. S., \& AbdElMoneim, S. A. 2015. Study of the C-reactive protein and tumor necrosis factor- $\alpha$ levels in the elderly before and after resistance exercise training. Egyptian Journal of Obesity, Diabetes and Endocrinology, 1(1), 7.

Salamat, K. M., Azarbayjani, M. A., Yusof, A., \& Dehghan, F. 2016. The response of pre-inflammatory cytokines factors to different exercises (endurance, resistance, concurrent) in overweight men. Alexandria Journal of Medicine, 52(4), 367-370.

Santiago, L. Â., Neto, L. G. L., Borges Pereira, G., Leite, R. D., Mostarda, C. T., de Oliveira Brito Monzani, J., Navarro, F. 2018. Effects of resistance training on immunoinflammatory response, TNF-alpha gene expression, and body composition in elderly women. Journal of aging research, 2018.

Shubert, T. E., Smith, M. L., Jiang, L., \& Ory, M. G. 2018. Disseminating the Otago exercise program in the United States: perceived and actual physical performance improvements from participants. Journal of Applied Gerontology, 37(1), 79-98.

Tomeleri, C. M., Ribeiro, A. S., Souza, M. F., Schiavoni, D., Schoenfeld, B. J., Venturini, D., Cyrino, E. S. 2016. Resistance training improves inflammatory level, lipid and glycemic profiles in obese older women: A randomized controlled trial. Experimental gerontology, 84, 80-87.

Visser, M., Pahor, M., Taaffe, D. R., Goodpaster, B. H., Simonsick, E. M., Newman, A. B., Harris, T. B. 2002. Relationship of interleukin-6 and tumor necrosis factor- $\alpha$ with muscle mass and muscle strength in elderly men and women: the Health ABC Study. The Journals of Gerontology Series A: Biological Sciences and Medical Sciences, 57(5), M326-M332. 